\title{
The Development of Students Worksheets Based on Outdoor Learning in Straight Motion Material for X Grade of Senior High School
}

\author{
Widia Hardiyanti ${ }^{* 1)}$, Zulhelmi ${ }^{2}$, Mitri Irianti ${ }^{33}$ \\ 1,2,3) Physics Education, University of Riau \\ e-mail: widia.hardiyanti@yahoo.co.id \\ emi_zain@yahoo.co.id \\ mitri.irianti@gmail.com
}

\begin{abstract}
Outdoor Learning-based physics student worksheets are task sheets that must be done by students that contain instructions for activities that will be used outside the classroom. This research aims to develop a valid physics worksheet based on outdoor learning on the material of straight motion for class X SMA. The type of research used is Research and Development $(R \& D)$ based research with a 4-D model design consisting of 4 stages of development, namely Define, Design, Develop, and Disseminate. Validation is carried out at the development stage by 3 validators who are experts and experienced in their fields and have experience. The instrument of this research is an assessment sheet in the form of a checklist. This research uses two types of data collected, namely quantitative data obtained from the score of the validation sheet assessed by the validator and student responses, while the qualitative data is in the form of criticism and suggestions from the validator on the product developed and a description of the implementation of product trials. Data analysis used descriptive analysis by calculating the index of each indicator used to determine the validity of the developed student worksheets. The results of this research provide an outdoor learning-based physics worksheet product which was developed on straight motion material which was declared valid from the presentation, linguistic, and graphic aspect with high and very high categories, so it was feasible to use in learning to support the teaching and learning process so that it became better.
\end{abstract}

Keywords: straight motion, student worksheets, outdoor learning. 


\title{
Pengembangan Lembar Kerja Peserta Didik Berbasis Outdoor Learning pada Materi Gerak Lurus Kelas X SMA
}

\author{
Widia Hardiyanti ${ }^{* 1)}$, Zulhelmi ${ }^{2)}$, Mitri Irianti ${ }^{3)}$ \\ ${ }^{112) 33}$ Pendidikan Fisika, Universitas Riau
}

\begin{abstract}
Abstrak
Lembar kerja peserta didik (LKPD) fisika berbasis Outdoor Learning adalah lembaran-lembaran tugas yang harus dikerjakan oleh peserta didik yang berisi petunjuk kegiatan yang akan digunakan di luar kelas. Tujuan utama penelitian ini adalah mengembangkan LKPD fisika yang valid berbasis Outdoor Learning pada materi gerak lurus kelas X SMA. Jenis penelitian yang digunakan adalah penelitian berbasis Research and Development (R\&D) dengan rancangan model 4-D yang terdiri dari 4 tahapan pengembangan yaitu Define (pendefinisian), Design (perencanaan), Develop (pengembangan), dan Disseminate (penyebaran). Pada tahap pengembangan dilakukan validasi oleh 3 orang validator yang ahli dan berpengalaman dibidangnya dan telah berpengalaman. Instrumen penelitian ini berupa lembar penilaian dengan bentuk checklist. Penelitian ini menggunakan dua jenis data yang dikumpulkan, yaitu data kuantitatif diperoleh dari skor lembar validasi yang dinilai oleh validator dan respon peserta didik, sedangkan data kualitatif berupa kritik dan saran validator terhadap produk yang dikembangkan dan deskripsi keterlaksanaan uji coba produk. Analisis data menggunakan analisis deskriptif dengan cara menghitung indeks dari setiap indikator yang digunakan untuk menentukan validitas LKPD yang dikembangkan. Hasil penelitian ini memberikan produk LKPD fisika berbasis Outdoor Learning yang dikembangkan pada materi gerak lurus yang dinyatakan valid dari aspek penyajian, aspek kebahasaan dan aspek kegrafisan dengan kategori tinggi dan sangat tinggi, sehingga layak digunakan dalam pembelajaran untuk menunjang proses belajar mengajar sehingga menjadi lebih baik.
\end{abstract}

Kata Kunci: gerak lurus, lembar kerja peserta didik, outdoor learning.

\section{Pendahuluan}

Indonesia saat ini menggunakan kurikulum 2013 yang bertujuan untuk memperbaiki kualitas peserta didik Indonesia agar mampu bersaing di masa mendatang. Kurikulum 2013 menuntut peserta didik berfikir ilmiah, menemukan konsep sendiri serta melaksanakan penilaian berbasis kompetensi. Oleh karena itu didalam proses belajar mengajar, guru harus memiliki strategi agar peserta didik dapat belajar secara efektif dan efisien serta mengena pada tujuan pembelajaran (Umaez, 2017).

Fenomena fisika kebanyakan bersifat abstrak, sehingga ilmu fisika menjadi salah satu ilmu yang tidak mudah dipelajari. Akibatnya peserta didik cenderung mebuat pendangan sendiri mengenai fenomena fisika. Konsep unik tentang fenomena alam yang di pahami peserta didik sering menjadi hambatan terhadap pengajaran karena konsep ini telah tertanam dalam pikiran peserta didik, terutama konsepsi yang diperoleh peserta didik dari pengalaman sehari-hari (Yusuf, 2008). Hal ini menyebabkan minat belajar fisika peserta didik sangat rendah. Untuk meningkatkan minat peserta didik dalam mempelajari fisika dan merubah persepsi peserta didik mengenai fisika itu sulit dan hanya belajar berupa rumus. Salah satu dari tujuan pembelajaran fisika adalah untuk menciptakan manusia yang mampu memecahkan masalah yang kompleks dengan cara mengimplementasi pengetahuan dan pemahaman mereka tersebut pada kehidupan sehari-hari. Sumber belajar yang digunakan peserta didik selama proses pembelajaran pada kurikulum 2013 yang tak terbatas, artinya sumber belajar tidak hanya dari buku pelajaran, namun juga dapat menggunakan lingkungan sekitar sebagai sumber belajar peserta didik.

Tujuan pembelajaran fisika yaitu meningkatkan kemampuan berpikir peserta didik, sehingga mereka tidak hanya mampu dan terampil dalam bidang psikomotorik dan 
kognitif, melainkan juga mampu menunjang berpikir sistematis, objektif dan kreatif (Nuris \& Edi, 2015). Peserta didik menganggap fisika sulit dikarenakan banyaknya rumus-rumus matematik dalam fisika yang harus dihafal. Salah satu materi fisika yang ada di SMA kelas $\mathrm{X}$ adalah materi gerak lurus.

Materi gerak lurus sulit dipahami jika hanya menggunakan metode ceramah, materi ini lebih mudah dipahamai dengan metode eskperimen, sehingga tidak hanya berupa rumus-rumus (Kayaman, 2015). Namun, kebanyakan sekolah tidak memiliki labor dan alat-alat eksperimen yang lengkap (Dedi et al., 2015). Salah satu usaha yang dilakukan untuk mewujdukan hal tersebut adalah dengan menerapkan pembelajaran berbasis outdoor learning, dimana pembelajaran dilakukan di luar kelas, sehingga dapat meningkatkan minat peserta didik agar tidak jenuh bila dibandingkan hanya belajar di dalam ruang kelas dan juga menggunakan lingkungan sebagai sumber belajar peserta didik. Untuk mendukung kegiatan outdoor learning agar tidak hanya sekedar belajar di luar ruang diperlukan LKPD sebagai tuntunan peserta didik dalam melakukan kegiatan di luar kelas. Berdasarkan hasil penelitian yang dilakukan Cintami \& Mukinan (2018) menyatakan bahwa metode outdoor learning efektif dalam meningkatkan hasil belajar kognitif peserta didik pada pelajaran geografi di sekolah menengah atas kota Palembang.

Pembelajaran di luar kelas (outdoor learning) merupakan upaya untuk mengarahkan peserta didik untuk melakukan aktivitas yang dapat membawa mereka mengamati lingkungan sekitar, sesuai dengan materi yang diajarkan. Sehingga pendidikan di luar kelas lebih mengacu pada pengalaman dan pendidikan lingkungan yang sangat berpengaruh pada kecerdasan peserta didik (Husamah, 2013). Pada metode outdoor learning ini peran guru hanya sebagai motivator, dimana guru sebagai pemandu kegiatan peserta didik agar belajar secara aktif, kreatif dan akrab dengan lingkungan. Dengan demikian diharapkan melalui metode ini peserta didik akan lebih tertarik lagi dalam mempelajari fisika.

Salah satu bentuk pembelajaran outdoor learning ini adalah praktikum lapangan. Praktikum tidak hanya dilakukan di ruang laboratorium, namun juga dapat dilakukan di luar ruangan (Hidayah, 2017). Pembelajaran praktikum adalah interaksi peserta didik dan guru, serta sumber belajar yang ada di lingkungan belajar tertentu yang memfasilitasi peserta didik untuk mempraktekkan secara empiris dengan menggunakan sarana laboratorium dalam menyelesaikan rubrik/ problem yang diberikan melalui penggunaan alat, bahan, metode tertentu, sehingga meningkatkan kemampuan kognitif, efektif, psikomotorik. Popov (2006) mengatakan bahwa kegiatan outdoor dilakukan dengan menggunakan peralatan yang cukup besar yang ada di sekitar kita. Misalnya untuk percobaan materi gerak lurus dapat digunakan mobil atau kereta api yang bergerak dan dihitung kecepatannya dengan terlebih dahulu mengukur jarak dan waktu yang dibutuhkan.

Outdoor learning atau penerapan pembelajaran di luar ruangan membuat peserta didik tidak lagi menghafal konsep, tetapi peserta didik dapat memahami secara langusng dan nyata terhadap pengetahuan mereka. Pembelajaran ini juga dapat mengembangkan keterampilan proses sains peserta didik secara langsung di lapangan, membuat pelajaran lebih jelas dan konkrit, dan peserta didik mudah untuk memahami pelajaran, merangsang peserta didik untuk lebih aktif mengamati dan mencoba sendiri, sehingga peserta didik lebih termotivasi dan antusias dalam pengamatan (Supahar, 2010). Pembelajaran di luar kelas (outdoor learning) merupakan salah satu upaya mengarahkan peserta didik untuk melakukan aktivitas sesuai dengan materi yang diajarkan dengan membawa mereka mengamati lingkungan sekitar.

Namun pembelajaran dengan Outdoor Learning ini tidak bisa hanya memindahkan tempat belajar dari dalam ruang ke luar ruang. Oleh karna itu, perlu dikembangkan Lembar Kerja Peserta Didik (LKPD) yang valid untuk digunakan pada pembelajaran yang menggunakan Outdoor Learning. Menurut Abdul Majid (2012), LKPD merupakan lembaranlembaran yang berisi tugas yang harus dikerjakan oleh peserta didik, isinya berupa petunjuk dan langkah-langkah untuk menyelesaikan suatu tugas dengan kejelasan kompetensi dasar yang harus dicapai. Penggunaan LKPD dapat dimanfaatkan untuk meningkatkan keterampilan berpikir kritis peserta didik, karna memuat kegiatan yang 
melibatkan proses penyelidikan dan pemecahan masalah didalamnya, guna mencapai kompetensi dasar yang harus dicapai.

Berdasarkan penelitian Muhammad Djajadi (2019) bahwa penggunaan metode Outdoor Learning dalam pembelajaran Fisika Kinematika dapat meningkatkan minat belajar peserta didik. Oleh karena itu, dalam kajian ini bertujuan membuat LKPD berbasis outdoor learning yang valid agar bisa digunakan oleh guru di sekolah pada materi gerak lurus kelas X SMA.

\section{Metode Penelitian}

Penelitian ini dilakukan pada pahun 2020 di laboratorium pengembangan pembelajaran fisika FKIP Universitas Riau. Objek penelitian adalah Lembar Kerja Peserta Didik (LKPD) berbasis outdoor learning pada materi gerak lurus kelas X.

Jenis penelitian yang digunakan adalah penelitian berbasis Research \& Development (R\&D) dengan model 4D. Model pengembangan yang digunakan terdiri dari empat tahap yaitu tahap pendefinisian (define), tahap perancangan (design), tahap pengembangan (develop) dan tahap penyebaran (disseminate) (Thiagarajan \& Semmel, 1974). Dalam penelitian ini dilakukan hanya sampai pada tahap pengembangan (develop). Tahap pendefinisian (define) berupa analisis awal, analisis peserta didik, analisis tugas, analisis konsep, serta spesifikasi tujuan pembelajaran. Tahap perancangan (design) dirancang LKPD yang dikembangakan, memuat materi, KI, KD, indikator dan tujuan pembelajaran, serta merancang kegiata-kegiatan yang akan dilakukan peserta didik di luar ruangan. Tahap pengembangan (develop) dilakukan validasi yang bertujuan untuk melihat tingkat validitas LKPD. Data yang digunakan yaitu data kuantitatif dan data kualitatif. Instrumen yang digunakan adalah angket validasi dengan bentuk checklist. Teknik pengumpulan data yang dilakukan adalah dengan menggunakan instrumen penilaian validasi, diisi oleh para ahli dibidangnya. Instrumen validitas LKPD dikembangkan sesuai dengan indikator instrumen validitas yang diadaptasi dari (BSNP, 2012; Revi et al., 2019).
Teknik analisis data menggunakan analisis deskriptif, yaitu dengan cara menghitung indeks dari setiap indikator yang digunakan untuk menentukan validitas LKPD yang dikembangkan. Kriteria penarikan kesimpulan penelitian dilakukan dengan cara masing-masing komponen penilaian isi perangkat pembelajaran dinyatakan valid, jika semua ahli (validator) telah memberikan penilaian masing-masing perangkat pembelajaran skor minimal 3.00 atau skor rata-rata tiap item penilaian minimal 3.00. Kategori rata-rata indikator ditentukan berdasarkan skala Likert seperti pada Tabel 1.

Tabel 1. Klasifikasi penilaian validitas

\begin{tabular}{ccc}
\hline Skor Rata-Rata & $\begin{array}{c}\text { Kriteria } \\
\text { Validasi }\end{array}$ & Kategori \\
\hline $3,50 \leq \bar{x} \leq 4,00$ & Valid & Sangat Tinggi \\
$3,00 \leq \bar{x} \leq 3,50$ & Valid & Tinggi \\
\hline
\end{tabular}

\section{Hasil dan Pembahasan}

Tahap pendefinisan peneliti melihat kurikulum yang berlaku pada saat ini, yaitu kurikulum SMA 2013 edisi revisi dan menganalisa kompetensi yang ingin dicapai. Kemudian pada tahap perancangan, peneliti merancang LKPD fisika berbasis outdoor learning. Lalu pada tahap pengembangan dilakukan validasi LKPD yang sudah dikembangkan seperti pada Gambar 1 oleh 3 para ahli dibidangnya. Pada tahap pengembangan ini dilakukan validasi oleh validator yang telah berpengalaman. Validator memberikan saran dan perbaikan terhadap LKPD yang dikembangkan agar menajad LKPD yang layak digunakan oleh peserta didik nantinya. Adapun saran dan perbaikannya adalah petunjuk yang ada di dalam LKPD diperjelas lagi, perbaikan pada tujuan pembelajaran agar lebih jelas, ukuran font pada LKPD dibesarkan agar lebih jelas, bahasa yang digunakan dirubah menjadi bahasa yang mudah dipahami oleh peserta didik, perbaikan tulisan yang salah dalam pengetikan LKPD, kejelasan soal-soal yang ada di dalam LKPD, perbaikan kalimat-kalimat di dalam LKPD. Adapun data kuantitatif hasil validasi dari para 
validator dari berbagai aspek, yaitu aspek kelayakan isi, aspek kelayakan penyajian, aspek kalayakan kebahasaan, dan aspek kelayakan kegrafisan diberikan pada uraian berikut.

Aspek kelayakan isi sebagai tolak ukur kelayakan materi yang ada di dalam LKPD sesuai dengan materi pembelajaran. Ada beberapa aspek yang dinilai untuk menyatakan validitas LKPD sesuai pada Tabel 2 yang menunjukan rata-rata hasil kelayakan isi dari
LKPD berada pada rentgang 3,42-3,46. Berdasarkan Tabel 2 dengan rentang tersebut maka secara keseluruhan LKPD yang dikembangkan berada pada kategori tinggi yaitu dengan skor 3,43 seperti pernyataan Prastowo (2012) bahwa LKPD yang baik harus memiliki kesesuaian antara materi dan kompetensi yang akan dicapai, sehingga diproleh LKPD yang sudah valid dari segi kelayakan.
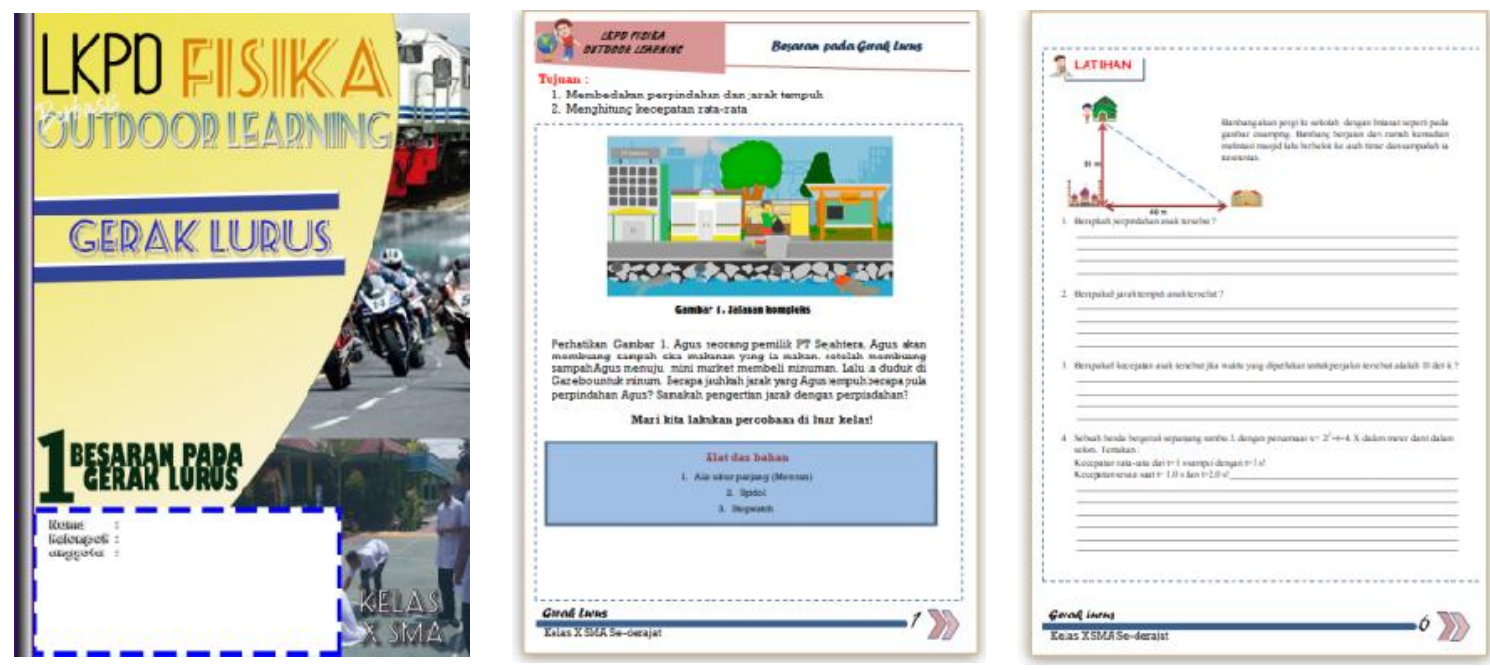

Gambar 1. Hasil Pengembangan LKPD Berbasis Outdoor Leaning.

Aspek kelayakan isi LKPD

Tabel 2. Hasil validasi kelayakan isi per-LKPD

\begin{tabular}{|c|c|c|c|c|c|}
\hline \multirow{2}{*}{ No } & \multirow{2}{*}{ Aspek } & \multicolumn{3}{|c|}{ LKPD } & \multirow{2}{*}{$\begin{array}{c}\text { Rata-Rata } \\
\text { Validasi }\end{array}$} \\
\hline & & 1 & 2 & 3 & \\
\hline 1 & $\begin{array}{l}\text { Kegiatan yang disajikan memuat } \\
\text { tujuan pembelajaran yang jelas }\end{array}$ & 3,33 & 3,67 & 4,00 & 3,67 \\
\hline 2 & Keakuratan fakta & 3,00 & 3,00 & 3,33 & 3,11 \\
\hline 3 & Kebenaran konsep & 3,67 & 3,33 & 3,00 & 3,33 \\
\hline 4 & $\begin{array}{l}\text { LKPD dapat menjalin interaksi sosial } \\
\text { antara peserta didik dengan peserta } \\
\text { didik maupun dengan guru }\end{array}$ & 4,00 & 3,67 & 4,00 & 3,89 \\
\hline 5 & Mendorong rasa ingin tahu & 4,00 & 4,00 & 4,00 & 4,00 \\
\hline 6 & $\begin{array}{l}\text { Contoh permasalahan kontekstual } \\
\text { terjadi dalam kehidupan sehari-hari }\end{array}$ & 3,33 & 3,33 & 3,33 & 3,33 \\
\hline 7 & $\begin{array}{l}\text { Menciptakan kemampuan bertanya } \\
\text { peserta didik }\end{array}$ & 3,00 & 3,33 & 3,00 & 3,11 \\
\hline 8 & $\begin{array}{l}\text { Terdapat unsur konstruktivis dalam } \\
\text { runtutan materi }\end{array}$ & 3,00 & 3,00 & 3,00 & 3,00 \\
\hline & Rata-Rata & 3,42 & 3,42 & 3,46 & 3,43 \\
\hline & Kategori & $\mathrm{T}$ & $\mathrm{T}$ & $\mathrm{T}$ & $\mathrm{T}$ \\
\hline & Kriterian Validitas & $\mathrm{V}$ & $\mathrm{V}$ & $\mathrm{V}$ & $\mathrm{V}$ \\
\hline
\end{tabular}


Aspek kelayakan penyajian LKPD

Tabel 3. Skor validasi kelayakan penyajian per LKPD

\begin{tabular}{|c|c|c|c|c|c|}
\hline \multirow{2}{*}{ No } & \multirow{2}{*}{ Aspek } & \multicolumn{3}{|c|}{ LKPD } & \multirow{2}{*}{$\begin{array}{c}\text { Rata-Rata Validas } \\
\text { Perindikator }\end{array}$} \\
\hline & & 1 & 2 & 3 & \\
\hline 1 & Urutan materi & 3,67 & 3,33 & 4,00 & 3,67 \\
\hline 2 & Kelengkapan judul tabel dan gambar & 3,67 & 4,00 & 3,67 & 3,78 \\
\hline 3 & $\begin{array}{l}\text { Kejelasan penomoran dan penamaan tabel } \\
\text { dan gambar }\end{array}$ & 3,33 & 3,33 & 3,33 & 3,33 \\
\hline \multirow[t]{4}{*}{4} & Keterlibatan peserta didik & 4,00 & 4,00 & 4,00 & 4,00 \\
\hline & Rata-Rata & 3,67 & 3,67 & 3,75 & 3,70 \\
\hline & Kategori & ST & ST & ST & ST \\
\hline & Kriteria Validasi & $\mathrm{V}$ & $\mathrm{V}$ & $\mathrm{V}$ & $\mathrm{V}$ \\
\hline
\end{tabular}

Berdasarkan Tabel 3 dari hasil penilaian validator menunjukan skor rata-rata untuk aspek kelayakan LKPD berada pada rentang 3,67-3,75 dimana LKPD 3 mempunyai skor rata-rata validasi tertinggi. Berdasarkan hasil rata-rata aspek kelayakan penyajian LKPD, maka secara keseluruhan hasil validasi LKPD berada pada kategori sangat tinggi. Hasil validasi aspek sajian telah sesuai dengan pendapat Darmodjo \& Kaligis dalam Indriyani (2013) bahwa salah satu syarat LKPD yang baik adalah menyediakan ruangan yang cukup untuk memberi keleluasaan pada peserta didik untuk menulis maupun menggambarkan pada LKPD.
Berdasarkan Tabel 3 untuk aspek kelayakan penyajian LKPD, indikator bahwa LKPD melibatkan peserta didik memperoleh skor tertinggi yaitu 4.00. Jadi, berdasarkan penilaian para validator LKPD ini dapat melibatkan peserta didik secara aktif, karna menurut Husamah (2013) metode pembelajaran di luar kelas dapat mengikutsertakan peserta didik berinteraksi langsung dan nyata dengan sumber belajar melalui pemanfaatan lingkungan sebagai sumber belajar, sehingga pembelajaran menjadi menyenangkan dan peserta didik dapat belajar secara aktif, bersemangat, dan antusias yang membuat pembelajaran lebih bermakna.

Aspek kelayakan kebahasaan LKPD

Tabel 4. Skor validasi kelayakan kebahasaan per LKPD

\begin{tabular}{|c|c|c|c|c|c|}
\hline \multirow{2}{*}{ No } & \multirow{2}{*}{ Aspek } & \multicolumn{3}{|c|}{ LKPD } & \multirow{2}{*}{$\begin{array}{c}\text { Rata-Rata Validas } \\
\text { Perindikator }\end{array}$} \\
\hline & & 1 & 2 & 3 & \\
\hline 1 & Mampuan memotivasi peserta didik & 3,33 & 3,00 & 3,00 & 3,11 \\
\hline 2 & Ketepatan penggunaan struktur kalimat & 3,00 & 3,00 & 3,00 & 3,00 \\
\hline 3 & Istilah yang digunakan baku & 3,00 & 3,00 & 3,00 & 3,00 \\
\hline 4 & $\begin{array}{l}\text { Penggunaan tata bahasa sesuai dengan } \\
\text { kaidah Bahasa Indonesia }\end{array}$ & 3,00 & 3,00 & 3,00 & 3,00 \\
\hline 5 & $\begin{array}{l}\text { Penggunaan ejaan yang sesuai dengan } \\
\text { kaidah Bahasa Indonesia }\end{array}$ & 3,00 & 3,00 & 3,00 & 3,00 \\
\hline 6 & $\begin{array}{l}\text { Konsistensi dalam penulisan nama } \\
\text { ilmiah/asing }\end{array}$ & 3,00 & 3,00 & 3,33 & 3,11 \\
\hline \multirow[t]{4}{*}{7} & $\begin{array}{l}\text { Sesuai dengan tahap perkembangan } \\
\text { intelektual peserta didik }\end{array}$ & 3,33 & 3,33 & 3,67 & 3,44 \\
\hline & Rata-Rata & 3,10 & 3,05 & 3,14 & 3,10 \\
\hline & Kategori & $\mathrm{T}$ & $\mathrm{T}$ & $\mathrm{T}$ & $\mathrm{T}$ \\
\hline & Kriteria Validasi & $\mathrm{V}$ & $\mathrm{V}$ & $\mathrm{V}$ & $\mathrm{V}$ \\
\hline
\end{tabular}


Aspek kelayakan kegrafisan LKPD

Tabel 5. Skor validasi kelayakan kegrafisan per LKPD

\begin{tabular}{|c|c|c|c|c|c|}
\hline \multirow{2}{*}{ No } & \multirow{2}{*}{ Aspek } & \multicolumn{3}{|c|}{ LKPD } & \multirow{2}{*}{$\begin{array}{l}\text { Rata-Rata Validasi } \\
\text { Perindikator }\end{array}$} \\
\hline & & 1 & 2 & 3 & \\
\hline 1 & $\begin{array}{l}\text { Tipografi huruf yang digunakan } \\
\text { dapat memudahkan pemahaman } \\
\text { peserta didik dan menarik }\end{array}$ & 3,33 & 3,00 & 3,00 & 3,11 \\
\hline 2 & $\begin{array}{l}\text { Desain, warna, pusat pandang, } \\
\text { komposisi, dan ukuran unsur tata } \\
\text { letak harmonis dan memperjelas } \\
\text { fungsi dari LKPD }\end{array}$ & 3,00 & 3,33 & 3,33 & 3,22 \\
\hline \multirow[t]{4}{*}{3} & $\begin{array}{l}\text { Ilustrasi yang ada mampu } \\
\text { memperjelas dan mempermudah } \\
\text { pemahaman peserta didik }\end{array}$ & 3,00 & 3,00 & 3,00 & 3,00 \\
\hline & Rata-Rata & 3,11 & 3,11 & 3,11 & 3,11 \\
\hline & Kategori & $\mathrm{T}$ & $\mathrm{T}$ & $\mathrm{T}$ & $\mathrm{T}$ \\
\hline & Kriteria Validasi & $\mathrm{V}$ & V & V & V \\
\hline
\end{tabular}

Ket. $\mathrm{ST}=$ =sangatnggi; $\mathrm{T}=$ tinggi; $\mathrm{R}=$ rendah; $\mathrm{V}=$ valid; $\mathrm{TV}=$ tidak valid

Penilaian aspek kelayakan kebahasaan menilai kepada efektivitas dan kesesuaian penggunaan bahasa didalam LKPD. Berdasarkan Tabel 4 rata-rata dari penilaian ketiga LKPD yaitu berada pada rentang 3,053,14 . Rata-rata penilaian aspek bahasa lebih rendah dibading dengan aspek kelayakan isi dan kelayakan penyajian. Berdasarkan hasil validasi oleh validator penggunaan bahasa didalam LKPD banyak perbaikan. Namun, ketiga LKPD berada pada rentang dengan kategori tinggi. Maka dari itu dapat dinyatakan bahwa ketiga LKPD ini dari aspek kebahasaan dinyatakan valid. BSNP (2006) menjelaskan bahwa bahan ajar cetak harus memperhatikan hal bahasa yang mudah, menyangkut: mengalirnya kosa kata, jelasnya kalimat, jelasnya hubungan kalimat, dan kalimat yang tidak terlalu panjang.

Berdasarkan Tabel 4 untuk aspek kelayak kebahasaan, indikator kesesuaian dengan perkembangan intelektual peserta didik memperoleh skor tertinggi dalam penilaian dari validator yaitu 3,44. LKPD yang dikembangkan ternyata sudah menggunakan bahasa yang sesuai dengan tingkat intelektual peserta didik, sehingga diharapkan ketika peserta didik mengerjakan LKPD ini tidak merasa kesulitan dengan bahasa yang digunakan karna berdasarkan penilaian dari validator bahasa yang digunakan sudah sesuai dengna tingkat perkembangan intelektual peserta didik yaitu tingkat SMA sederajat.

Penilaian aspek kegrafisan melihat pada desain dan tipografi huruf yang digunakan dalam LKPD. Berdasarkan hasil penilaian oleh validator pada Tabel 5 rata-rata nilai validasi berada pada skor 3,11 untuk ketiga LKPD. Berdasarkan hasil tersebut, LKPD berada pada kategori tinggi dan dinyatakan valid pada aspek kelayakan kegrafisan. Berdasarkan Tabel 5, hasil penilaian validator untuk indikator yang ada di dalam aspek kegrafisan, indikator desain penampilan, warna, pusat pandang, komposisi, dan ukuran unsur tata letak harmonis dan memperjelas fungsi memperoleh skor tertinggi yaitu 3,22. Berdasarkan penilaian tersebut, maka LKPD yang dikembangkan memiliki penampilan yang dapat memperjelas fungsi dari LKPD yang dikembangkan.

Hasil penelitian menunjukkan bahwa LKPD yang dikembangkan sudah valid dari segi kelayakan isi, kelayakan penyajian, kelayakan kebahasaan dan kelayakan kegrafisan dengan kategori validitas berada pada kategori tinggi dan sangat tinggi, sehingga LKPD ini sudah layak untuk digunakan didalam pembelajaran. 
Dengan demikian, tentunya LKPD yang valid dapat menunjang proses belajar mengajar, sehingga menjadi lebih baik. Diharapkan LKPD ini dapat dilanjutkan ke tahap penyebaran (disseminate), dimana tahap penyebaran merupakan tahap penggunaan LKPD yang dikembangkan pada skala luas dan bertujuan untuk mengetahui efektivitas penggunaan LKPD dalam proses pembelajaran.

\section{Kesimpulan}

LKPD fisika berbasis Outdoor Learning pada materi gerak lurus telah berhasil dikembangkan dan sudah dinyatakan valid dari segi aspek kelayak isi, aspek kelayakan penyajian, aspek kelayakan kebahasaan dan aspek kelayakan kegrafisan dengan kategori setiap aspek tinggi dan sangat tinggi. LKPD ini sudah dapat digunakan dalam pembelajaran untuk menunjang proses belajar mengajar di sekolah, sehingga peserta didik lebih tertaarik dalam belajar fisika. LKPD dapat diterapkan dengan uji coba LKPD dan sampai pada tahap penyebaran untuk mengetahui efektivitas penggunaannya dalam proses pembelajaran.

\section{Daftar Pustaka}

Abdul Majid. (2012). Perencanaan Pembelajaran Mengembangkan Standar Kompetensi Guru. Bandung: PT. Remaja Rosdakarya.

BSNP. (2006). Panduan Penyusunan Kurikulum Tingkat Satuan Pendidikan Jenjang Pendidikan Dasar dan Menengah. Jakarta: Depdiknas.

Cintami \& Mukinan. (2018). Efektivitas outdoor study untuk meningkatkan hasil belajar Geografi berdasarkan locus of control di sekolah menengah atas Kota Palembang. Jurnal Ilmu-Ilmu Sosial, 15(2), 164-17.

Dedi, R., Adlim, \& Mustanir. (2015). Analisis keterlaksanaan kegiatan praktikum di SLTA Aceh besar, mengumpulkan masalah dan kendala pelaksanaan praktikum serta mencari solusi alternatif pemecahan masalah- masalah tersebut berdasarkan kajian literatur dan pendapat ahli. .Jurnal Pendidikan Sains Indonesia, 03(02), 01-13.

Hidayah, M. (2017). Pengembangan Instrumen Penilaian Psikomotor pada Oudoor Practicum Biologi SMA. Didaktika, 1(2), 143-148.

Husamah. (2013). Pembelajaran Luar Kelas Outdoor Learning: Rancangan trategis Mengembangkan Metode Pembelajaran Yang Menyenangkan, Inovatif \& Menantang. Jakarta: Prestasi Pustaka.

Indriyani. (2013). Mengembangkan Penguasaan Konsep Sains dan karakter siswa Melalui Pembelajaran Berbasis Bimbingan. Universitas Pendidikan Indonesia. Repository. upi.edu.

Kayaman. (2015). Pengaruh metode eksperimen, motivasi dan keaktifan belajar terhdapa hasil belajar pada pokok bahasan gerak lurus pada siswa SMA Negeri 1 AIMAS, Kabupaten Sorong. Jurnal Ilmu Pendidikan Indonesia, 3(3), 45-53.

Muhammad Djajadi. (2019). The Use of Outdoor Study Methods in Physics Kinematics Learning (A Classroom Action Research). Journal of Physics Education. 7(2), 151-172.

Nuris, S. P., \& Edi, S. (2015). Studi Pelaksanaan Pembelajaran Berbasis HOTS Pada kelas X Di SMA Negeri Kota Yogyakarta. Jurnal Nasional Fisika dan Pendidikan Fisika, 6(1), 104-116.

Popov, O. (2006). Developing Outdoor Activities and a Website as resources to Stimulate Learning Physics in Teacher Education. Journal Physics Teacher. Education Online, 3(3),18-2.

Prastowo. (2012). Panduan Kreatif Membuat Bahan Ajar Inovatif. Yogyakarta: Diva Press.

Revi, N. R., Zulhelmi, \& Syahril. (2019). Pengembangan lkpd fisika berbasis contextual Teaching and learning pada materi fluida dinamis Untuk kelas xi sma. Jom FKIP-UR, 6(2), 1-9. JuliDesember 2019.

Supahar. (2010). Menanamkan Keterampilan Proses Sains IPA pada Siswa dengan Strategi Pembelajaran Outdoor Activities dalam Kegiatan Lesson Study Berbasis Sekolah (LSBS). Journal of Physics Education $\quad$ Online, 3(3). 
http://journal.student.uny.ac.id/jurnal/edis i/78/46.pdf.

Thiagarajan, S., Semmel, D. S., \& Semmel, M. I. (1974). Instructional development for training teacher of exceptional children. Bloomington Indiana: Indiana University. Umaez, A. (2017). Pengembangan Metode Demonstrasi Menggunakan Lembar Kerja
Siswa Simulasi Online pada Materi Fluida. Jurnal Penelitian Pembelajaran Fisika, 8(2). 95-100.

Yusuf, M. (2008). Multirepresentasi dalam Pembelajaran Fisika. JURDIK Fisika FKIP Universitas Sriwijaya. 